mediated immune function in elderly long-stay patients: a randomised controlled trial. Age Ageing 1991;20:169-74.

13 Goode HF, Kelleher J, Walker BE, Hall RI, Guillou PJ. Cellular and muscle zinc in surgical patients with and without gastrointestinal cancer. Clin $\mathrm{Sc}$ 1990;79:247-52.

14 Goode HF, Kelleher J, Walker BE. Zinc concentrations in pure populations of peripheral blood neutrophils, lymphocytes and monocytes. Ann Clin Biochem 1989;26:89-95.

15 Catignami GL, Bieri JG. Simultaneous determination of retinol and (2tocopherol in serum or plasma by liquid chromatography. Clin Chem 1983;29:708-12.

16 Denson KW, Bowers EF. The determination of ascorbic acid in white blood cells. Clin Sci 1961;21:157-62.
17 Morgan AG, Kelleher J, Walker BE, Losowsky MS, Droller H, Middleton RSW. A nutritional survey in the elderly: blood and urine vitamin levels. Int $\mathcal{F}$ Vitam Nutr Res 1975;45:448-62.

18 Brown KM, Seabrook NA. Nutritional influences on recovery and length of hospital stay in elderly women following femoral fracture [abstract]. Proc Nutr Soc (in press)

19 Schorah CJ, Habibzadeh N, Hancock M, King RFGJ. Changes in plasma and buffy layer vitamin $C$ concentrations following major surgery: what do they reflect? Ann Clin Biochem 1986;23:566-70.

20 Taylor TV, Rimmer S, Day B, Butcher J, Dymock IW Ascorbic acid supplementation in the treatment of pressure sores. Lancet 1974;ii:544-6.

(Accepted 1 September 1992

\title{
Comparison of Yuzpe regimen, danazol, and mifepristone (RU486) in oral postcoital contraception
}

\author{
Anne M C Webb, Jean Russell, Max Elstein
}

\begin{abstract}
Objective-To compare the effectiveness and acceptability of three regimens of postcoital contraception.

Design-Randomised group comparison of ethinyloestradiol $100 \mu \mathrm{g}$ plus levonorgestrel $500 \mu \mathrm{g}$ repeated after 12 hours (Yuzpe method); danazol 600 $\mathrm{mg}$ repeated after 12 hours; and mifepristone $600 \mathrm{mg}$ single dose.
\end{abstract}

Setting-Community family planning clinic.

Subjects-616 consecutive women with regular cycles aged 16 to 45 years.

Main outcome measures-Number of pregnancies, incidence of side effects, and timing of next period.

Results-The raw pregnancy rates (with 95\% confidence intervals) for the Yuzpe, danazol, and mifepristone groups were $2.62 \%(0.86 \%$ to $6.00 \%)$, $4 \cdot 66 \%(2 \cdot 15 \%$ to $8 \cdot 67 \%)$, and $0 \%(0 \%$ to $1 \cdot 87 \%)$ respectively. Overall, these rates differed significantly $\left(\chi^{2}=8.988, \mathrm{df}=2 ; \mathrm{p}=0.011\right)$. The differences between the mifepristone and Yuzpe groups and between the mifepristone and danazol groups were also significant. Side effects were more common and more severe in the Yuzpe group (133 women (70\%)) than in either the danazol group $(58(30 \%))$ or the mifepristone group ( $72(37 \%))$. The Yuzpe regimen tended to induce bleeding early but mifepristone prolonged the cycle. Three women bled more than seven days late in the Yuzpe group compared with 49 in the mifepristone group.

Conclusions-Mifepristone was effective in University of Manchester, Department of Obstetrics and Gynaecology, Palatine Centre, Manchester M20 9LJ

Anne M C Webb, clinical research fellow

\section{Department of Medical} Statistics, University

Hospital of South Manchester, Manchester M20 8LR

Jean Russell, medical statistician

Department of Obstetrics and Gynaecology, University Hospital of South Manchester, Manchester M20 8LR Max Elstein, professor

Correspondence and requests for reprints to: Dr Webb.

$B M \mathcal{1 9 9 2 ; 3 0 5 : 9 2 7 - 3 1}$ to oestrogen treatment and suggested the Yuzpe regimen was preferable because of the shorter duration pregnancies is difficult but a reduced incidence has been shown when compared with numbers predicted of treatment. ${ }^{5}$ Estimating the numbers of expected by various methods. ${ }^{26.9}$ The Yuzpe regimen has become an accepted and recommended method of postcoital contraception..$^{10}$

Danazol has been suggested to be as effective as the Yuzpe method with fewer side effects."112 The antiprogesterone drug mifepristone has been shown to be an effective abortifacient and has been used as an interceptive and menstrual regulator, ${ }^{13.15}$ although it causes considerable cycle upset. 1617 We conducted a study to compare the effectiveness and side effects of these three methods (Yuzpe, danazol, mifepristone).

\section{Subjects and methods}

Women requesting emergency contraception after only one act of unprotected intercourse during their current cycle were considered for study if they presented within 72 hours of the act. Only women with regular cycles were included. The length of the cycle could vary from 21 to 35 days, but for one individual the variation over the previous three months could not exceed four days. Women who had been pregnant in the previous three months were excluded. The study was restricted to women who were aged 16-45 years, willing to sign consent, and available for follow up. Women with contraindications to oestrogen or progestogen (thromboembolic disease, liver disease, breast cancer, diabetes, jaundice, or pruritus of pregnancy), with known or suspected adrenal disease, or who were taking interacting drugs (liver enzyme inducers, broad spectrum antibiotics) were excluded. No woman had taken any sex steroids since her last menstruation. All women were interviewed by the same person $(A M C W)$

The date of the last menstruation, cycle length, and exact time of unprotected intercourse were noted. Any use of contraception (coitus interruptus, failed barrier), height, weight, and previous pregnancies and their outcome were recorded. Serum progesterone concentration was measured by quantitative radioimmunoassay.

Subjects were randomly allocated to receive the Yuzpe regimen (ethinyloestradiol $100 \mu \mathrm{g}$ and levonorgestrel $500 \mu \mathrm{g}$ repeated after 12 hours), danazol 600 $\mathrm{mg}$ repeated after 12 hours, or mifepristone $600 \mathrm{mg}$ one dose only. The allocation schedule was constructed by using a computer based pseudorandom number generator with a uniform distribution. The schedule was prepared before the start of the study by JR, who did not participate in either the selection or assessment of women. The mifepristone was always taken in the clinic. The other two drug regimens were also always started within 72 hours of unprotected intercourse but the first dose was often taken after the visit to the clinic to obviate taking the tablets on an empty stomach or 
having to wake up in the middle of the night for the second dose.

Each woman was given a diary card on which to record any vaginal bleeding, nausea, vomiting, breast tenderness, any other side effects, and concomitant drugs. She was seen again just after her next menstruation was expected (taking into account her last bleed and cycle length) and the date and amount of bleeding were recorded. If pregnancy was suspected serum was taken to measure $\beta$ human chorionic gonadotrophin concentration by quantitative radioimmunoassay. If the result was positive the various options, including termination of pregnancy, were discussed.

The study was approved by the local (South Manchester District Health Authority) and World Health Organisation ethics committees.

\section{STATISTICAL METHODS}

A pregnancy rate of $7 \%$ was assumed in the absence of postcoital treatment. ${ }^{2}$ Pregnancy rates of around $2 \%$ are most commonly reported for the Yuzpe method. ${ }^{18}$ Power calculations showed that 356 patients would be required to show this difference to be significant at the conventional $5 \%$ level with $90 \%$ power for two groups. We adopted a sample size of 1200 to compensate for the addition of a third group. A preplanned interim analysis at 600 completed patients showed that some of the treatment differences were much greater than expected and it was considered unethical to continue the study. Patients currently in the study were followed up, giving a total sample size of 616 .

The proportions of women in each treatment group experiencing appropriate clinical events were calculated with $95 \%$ confidence intervals where indicated. ${ }^{19}$ For each treatment group pregnancy rates and standardised ratios (number of observed pregnancies divided by number expected) were computed with $95 \%$ confidence intervals. ${ }^{19}$ Various methods of estimating risk of pregnancy have been suggested. ${ }^{2-4}$ We used the risk tables of Dixon et al, who combined the different estimates to produce a risk for each day of the cycle.

\section{Results}

A total of 616 women were recruited: $27(4 \cdot 4 \%)$ were lost to follow up or had unusable results and $23(3 \cdot 7 \%)$ women had a partial follow up. This group included women who had been followed up very late (for whom the only information available was that they had not been pregnant) and women who had had further acts of unprotected intercourse in the cycle (who had taken further postcoital contraception). In the last group side effects could be assessed but not effectiveness or date of

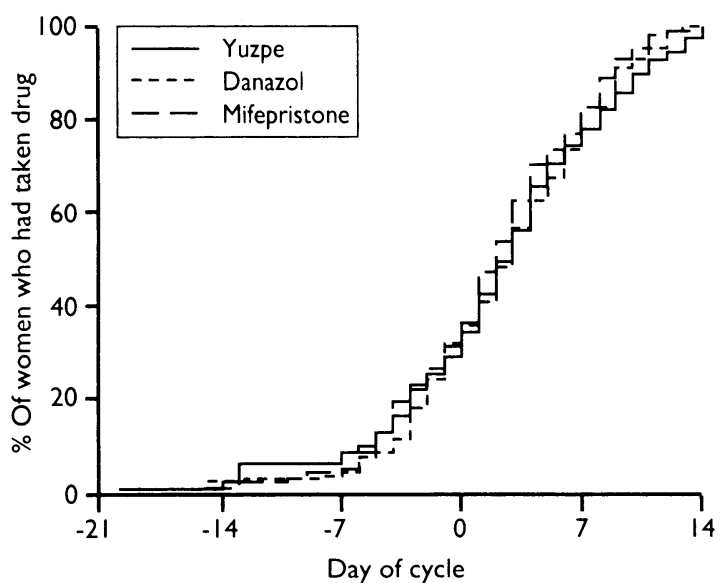

FIG 1-Cumulative graph showing percentage of women having taken treatment by day of cycle. Day of cycle is expressed relative to predicted day of ovulation, which was calculated by adding usual cycle length to day of last menstrual period and subtracting 15

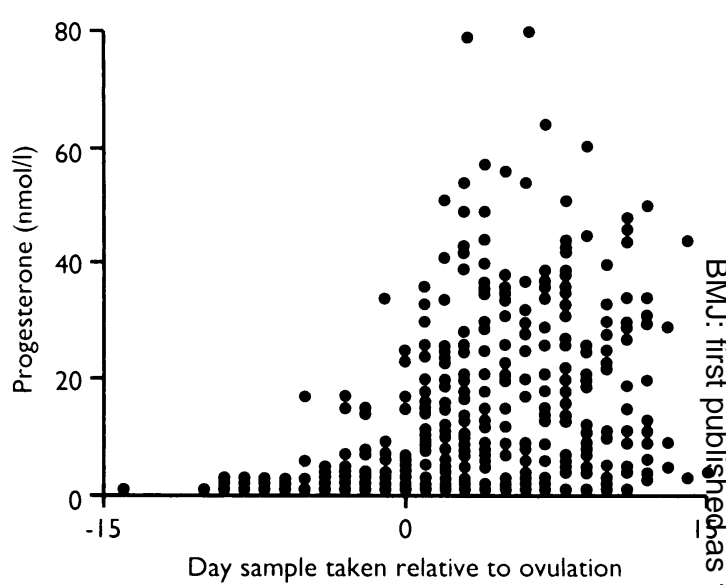

FIG 2-Progesterone concentration at time of clinic visit relative estimated day of ovulation

next period. None of these women became pregnan $\frac{\sigma}{6}$ Consequently, the occurrence of pregnancy could be assessed in $579(94 \%)$ women, the incidence of sidi effects in $581(94 \%)$ women, and the timing of the nex bleed in $566(92 \%)$

Table I shows the characteristics of the women an type of contraception used, if any.

TABLE I-Method of contraception, previous proved fertility, and ag of women for whom it was possible to assess effectiveness of treatment

\begin{tabular}{|c|c|c|c|}
\hline & $\begin{array}{l}\text { No }(\%) \\
\text { receiving } \\
\text { Yuzpe } \\
\text { regimen }\end{array}$ & $\begin{array}{c}\text { No }(\%) \\
\text { receiving } \\
\text { danazol }\end{array}$ & $\begin{array}{c}\text { No(\%) } \\
\text { receiving } \\
\text { mifepriston@ }\end{array}$ \\
\hline \multicolumn{4}{|c|}{ Method of contraception used: } \\
\hline None & $54(28)$ & $62(32)$ & $56(29)$ है \\
\hline Sheath & $133(70)$ & $119(62)$ & $130(67) !$ \\
\hline Coitus interruptus & $2(1)$ & $11(6)$ & $7(4)$ \\
\hline Other & 2(1) & $1(1)$ & $2(1)$ \\
\hline \multicolumn{4}{|l|}{ Fertility proved: } \\
\hline No & $140(73)$ & $142(74)$ & $133(68)$ \\
\hline Yes & $51(27)$ & $51(26)$ & $62(32) \mathrm{O}$ \\
\hline \multicolumn{4}{|l|}{ Age range (years): } \\
\hline $16-20$ & $64(34)$ & $63(33)$ & $60(31) \bar{\triangle}$ \\
\hline $21-25$ & $69(36)$ & $78(40)$ & $78(40)$ ㅇ \\
\hline $26-30$ & $40(21)$ & $30(16)$ & $35(18) \overline{\overline{7}}$ \\
\hline $31-35$ & $12(6)$ & $11(6)$ & $14(7) \cong$ \\
\hline$\geqslant 36$ & $6(3)$ & $11(6)$ & $8(4)$ \\
\hline Total & 191 & 193 & 195 \\
\hline
\end{tabular}

Most women (412) were under 25 years old. The young age of most women was also reflected in the largo number (415) who had never been pregnant. Two thirds of the women had used a barrier which hag failed. Although a few had used diaphragms, most had used sheaths which had split or come off.

Figure 1 shows the timing of taking postcoita contraception relative to the time of expected ovula tion. The distribution was similar in all three treatme groups. Figure 2 shows the serum progesterone: concentrations at presentation. They were consister with the time of the cycle as calculated by the date the last period and cycle length.

PREGNANCIES

The probability of pregnancy calculated from estimates published by Dixon et $a l^{2}$ predicted 34.7 pregnancies overall; 14 were observed (table II).

Only five pregnancies occurred in the Yuzpe groug in which 11.3 were predicted. One woman had had intercourse the day before predicted ovulation using sheath. Four women had used no contraception: two had had intercourse on the day of expected ovulationg one two days after expected ovulation, and one three days after.

In the danazol group 11.7 pregnancies were predicted and nine observed. Six of these women had used a sheath. Two pregnancies were conceived late in the cycle: one women later admitted to sometimes having a 


\begin{tabular}{|c|c|c|c|c|c|c|c|c|c|c|}
\hline \multirow[b]{2}{*}{$\begin{array}{l}\text { Day of } \\
\text { cycle }\end{array}$} & \multirow{2}{*}{$\begin{array}{l}\text { Probability } \\
\text { of } \\
\text { pregnancy }\end{array}$} & \multicolumn{3}{|c|}{ Yuzpe } & \multicolumn{3}{|c|}{ Danazol } & \multicolumn{3}{|c|}{ Mifepristone } \\
\hline & & $\begin{array}{c}\text { No of } \\
\text { women }\end{array}$ & Expected & Observed & $\begin{array}{c}\text { No of } \\
\text { women }\end{array}$ & Expected & Observed & $\begin{array}{c}\text { No of } \\
\text { women }\end{array}$ & Expected & Observed \\
\hline$<-8$ & 0.000 & 5 & $0 \cdot 000$ & 0 & 2 & $0 \cdot 000$ & 0 & 5 & $0 \cdot 000$ & 0 \\
\hline-8 & 0.001 & 6 & 0.006 & 0 & 6 & 0.006 & 0 & 3 & 0.003 & 0 \\
\hline-7 & 0.007 & 3 & 0.021 & 0 & 3 & $0 \cdot 021$ & 0 & 4 & 0.028 & 0 \\
\hline-6 & 0.025 & 9 & 0.225 & 0 & 4 & $0 \cdot 100$ & 0 & 11 & $0 \cdot 275$ & 0 \\
\hline-5 & 0.055 & 11 & 0.605 & 0 & 13 & 0.715 & 0 & 7 & 0.385 & 0 \\
\hline-4 & $0 \cdot 104$ & 8 & 0.832 & 0 & 11 & $1 \cdot 144$ & 1 & 9 & 0.936 & 0 \\
\hline-3 & $0 \cdot 146$ & 8 & $1 \cdot 168$ & 0 & 12 & 1.752 & 0 & 9 & 1.314 & 0 \\
\hline-2 & 0.169 & 5 & 0.845 & 0 & 11 & 1.859 & 0 & 6 & 1.014 & 0 \\
\hline-1 & 0.173 & 13 & $2 \cdot 249$ & 1 & 9 & 1.557 & 1 & 16 & $2 \cdot 768$ & 0 \\
\hline 0 & $0 \cdot 141$ & 23 & $3 \cdot 243$ & 2 & 15 & $2 \cdot 115$ & 0 & 15 & $2 \cdot 115$ & 0 \\
\hline 1 & 0.091 & 10 & 0.910 & 0 & 16 & 1.456 & 3 & 23 & 2.093 & 0 \\
\hline 2 & $0 \cdot 049$ & 18 & 0.882 & 1 & 15 & 0.735 & 1 & 7 & $0 \cdot 343$ & 0 \\
\hline 3 & 0.019 & 14 & $0 \cdot 266$ & i & 11 & 0.209 & 1 & 19 & $0 \cdot 361$ & 0 \\
\hline 4 & 0.005 & 6 & 0.030 & 0 & 11 & 0.055 & 0 & 9 & 0.045 & 0 \\
\hline 5 & 0.001 & 8 & 0.008 & 0 & 11 & 0.011 & 0 & 10 & 0.010 & 0 \\
\hline$>5$ & 0.000 & 44 & $0 \cdot 000$ & 0 & 43 & 0.000 & 2 & 42 & $0 \cdot 000$ & 0 \\
\hline Total & & 191 & $11 \cdot 290$ & 5 & 193 & $11 \cdot 735$ & 9 & 195 & $11 \cdot 690$ & 0 \\
\hline \multirow{2}{*}{\multicolumn{2}{|c|}{$\begin{array}{l}\text { Pregnancy rate }(95 \% \text { confidence interval }) \\
\text { Standardised ratio }(95 \% \text { confidence } \\
\text { interval })\end{array}$}} & \multicolumn{3}{|c|}{$2.62(0.86$ to 6.00$)$} & \multicolumn{3}{|c|}{$4 \cdot 66(2 \cdot 15$ to $8 \cdot 67)$} & \multicolumn{3}{|c|}{$0.00(0.00$ to 1.87$)$} \\
\hline & & \multicolumn{3}{|c|}{$0.443(0 \cdot 144$ to $1 \cdot 030)$} & \multicolumn{3}{|c|}{$0.767(0.351$ to 1.460$)$} & \multicolumn{3}{|c|}{$0.000(0.000$ to 0.316$)$} \\
\hline
\end{tabular}

*The day of the cycle is expressed relative to the day of expected ovulation (day 0 ). This was calculated by adding the usual cycle length to the day of last menstrual period and subtracting 15 .

longer cycle, but the other apparently conceived on day 24 of a regular 28 day cycle.

In the mifepristone group 11.7 pregnancies were predicted. No clinical pregnancies were observed, though one woman had a $\beta$ human chorionic gonadotrophin concentration of 149 IU/l 19 days after unprotected intercourse. The concentration fell spontaneously and she bled 14 days late. An endometrial biopsy showed decidual reaction but no chorionic villi.

Five other pregnancies were observed which were not conceived at the time of the unprotected intercourse. Two women were pregnant when presenting despite having had a bleed at the expected time within the previous three weeks. This was confirmed by the finding of $\beta$ human chorionic gonadotrophin concentrations above $500 \mathrm{IU} / 1$ in the blood sample taken to measure progesterone at presentation. One woman took mifepristone and at the follow up visit four weeks later had a $\beta$ human chorionic gonadotrophin concentration of $21 \mathrm{IU} / \mathrm{l}$. She had a heavier than normal bleed 30 days after treatment. The second woman took the Yuzpe regimen and her pregnancy continued.

Three women, all in the mifepristone group, conceived between the time of treatment and the follow up visit, one about 10 days after and two about 15 or 16 days after the reported date of unprotected intercourse. All women had been urged to use adequate contraception in the immediate future as the treatment given could give cover only for the previous 72 hours. The three women who conceived after mifepristone treatment said they had subsequently used sheaths with no obvious problems.

Delayed conception was suspected when the concentration of chorionic gonadotrophin at the follow up visit was less than expected for a normal pregnancy conceived at the time of the reported unprotected intercourse. ${ }^{20}$ By repeating the measurement and obtaining one or more ultrasound scans, normal pregnancies conceived later than the reported date were confirmed. One of these women had a very light bleed three days after taking mifepristone and her chorionic gonadotrophin concentration and ultrasound scan agreed with a normal conception two weeks after this bleed. The other two reported no bleeding. As these three pregnancies were clearly not conceived at the time of the reported unprotected intercourse they cannot be considered failures of the mifepristone treatment and have been excluded from the analysis.
PREGNANCY RATES

The raw pregnancy rates (with $95 \%$ confidence intervals) for the Yuzpe, danazol, and mifepristone groups were $2 \cdot 62 \%(0 \cdot 86 \%$ to $6 \cdot 00 \%), 4 \cdot 66 \%(2 \cdot 15 \%$ to $8 \cdot 67 \%)$, and $0 \%(0 \%$ to $1 \cdot 87 \%)$ respectively. Overall these rates differed significantly $\left(\chi^{2}=8.988, \mathrm{df}=2\right.$; $\mathrm{p}=0.011)$. Breaking this test down into a series of pairwise comparisons showed a non-significant difference between the mifepristone and Yuzpe groups $(p=0.061)$ and a significant difference between the mifepristone and danazol groups $(p=0 \cdot 004)$. Although the failure rate in the danazol group was nearly twice that in the Yuzpe group, the difference was not significant at the conventional level.

A comparison of raw pregnancy rates takes no account of expected rates. Standardised ratios were therefore calculated for the three groups (table II). These rates cannot be formally compared because no pregnancy was observed in the mifepristone group, but the findings for raw pregnancy rates are clearly replicated. The standardised ratios show that the number of observed pregnancies in the danazol group did not differ significantly from the number of expected pregnancies if no treatment had been given. There was a significant difference from the expected number for the mifepristone group $(p<0.001)$ and a significant difference for the Yuzpe regimen $(p=0 \cdot 061)$.

OUTCOME OF PREGNANCIES

Two women in the Yuzpe group continued their pregnancies and had vaginal deliveries of normal female infants. The other three had induced abortions. In the danazol group eight women had induced abortions and one delivered a normal male infant. Of the three women who got pregnant after taking mifepristone one continued her pregnancy and had a vaginal delivery of a normal male and two had induced abortions. The woman who was already pregnant when given the Yuzpe regimen had an induced abortion.

\section{SIDE EFFECTS}

Women in the Yuzpe group experienced more nausea and vomiting than those in the two others (table III). In the Yuzpe group $133(70 \%)$ women experienced nausea, of whom 36 said it was severe. By comparison $58(30 \%)$ of the women in the danazol group and $72(37 \%)$ in the mifepristone group complained of nausea with only four $(2 \%)$ and six $(3 \%)$ women rating the symptoms as severe. The pattern for vomiting was similar. Almost a quarter (42) of the Yuzpe group experienced vomiting, of whom $12(6 \%)$ 
stated it was severe. One woman vomited so severely she was unable to take the second dose and resorted to an intrauterine device for postcoital contraception Only six (3\%) women in the danazol group and $5(3 \%)$ in the mifepristone group experienced any vomiting. The only subject who had severe vomiting was the woman who developed an allergic reaction to danazol, which settled by the next day with no further treatment.

Breast tenderness was similar in all three groups (table III). A few women experienced other side effects including headache, tiredness, lethargy, and dizziness. None of these symptoms was rated as severe.

\section{BLEEDING PATTERNS}

Table IV shows the timing of bleeding relative to the expected first day of menstruation. Figure 3 shows the cumulative graph of time of bleeding relative to predicted day of next menstruation in each group. The

TABLE III-Side effects experienced in the first four days after taking treatment

\begin{tabular}{lccc}
\hline & $\begin{array}{c}\text { No }(\%) \text { of } \\
\text { women } \\
\text { receiving } \\
\text { Yuzpe } \\
(\mathrm{n}=191)\end{array}$ & $\begin{array}{c}\text { No }(\%) \text { of } \\
\text { women } \\
\text { receiving } \\
\text { danazol } \\
(\mathrm{n}=193)\end{array}$ & $\begin{array}{c}\text { No }(\%) \text { of } \\
\text { women } \\
\text { receiving } \\
\text { mifepristone } \\
(\mathrm{n}=197)\end{array}$ \\
\hline Nausea: & & & \\
$\quad$ None & $58(30)$ & $135(70)$ & $125(63)$ \\
Mild & $49(26)$ & $40(21)$ & $44(22)$ \\
Moderate & $48(25)$ & $14(7)$ & $22(11)$ \\
Severe & $36(19)$ & $4(2)$ & $6(3)$ \\
Vomiting: & $149(78)$ & $187(97)$ & $192(97)$ \\
$\quad$ None & $17(9)$ & $5(3)$ & $4(2)$ \\
Mild & $13(7)$ & $1(1)$ & $1(1)$ \\
Moderate & $12(6)$ & & \\
Severe & $157(82)$ & $154(80)$ & $163(83)$ \\
Breast tenderness: & $27(14)$ & $28(15)$ & $27(14)$ \\
$\quad$ None & $7(4)$ & $9(5)$ & $7(4)$ \\
Mild & & $2(1)$ & \\
Moderate & $186(97)$ & $192(99)$ & $194(98)$ \\
Severe & $5(3)$ & $1(1)$ & $3(2)$ \\
Other side effects: & & & \\
$\quad$ No & & & \\
Yes & & & \\
\hline
\end{tabular}

TABLE IV-Timing of menstruation after taking postcoital contraception

\begin{tabular}{lcrc}
\hline $\begin{array}{l}\text { Timing of menstruation } \\
\text { relative to expected first } \\
\text { day of period }\end{array}$ & $\begin{array}{c}\text { No (\%) } \\
\text { receiving } \\
\text { Yuzpe }\end{array}$ & $\begin{array}{c}\text { No (\%) } \\
\text { receiving } \\
\text { danazol }\end{array}$ & $\begin{array}{c}\text { No (\%) } \\
\text { receiving } \\
\text { mifepristone }\end{array}$ \\
\hline$<-7$ & $42(23)$ & $21(11)$ & $10(5)$ \\
-7 to -4 & $29(16)$ & $36(19)$ & $26(14)$ \\
-3 to 3 & $95(51)$ & $107(56)$ & $69(37)$ \\
4 to 7 & $9(5)$ & $7(4)$ & $24(13)$ \\
$>7$ & $3(2)$ & $10(5)$ & $49(26)$ \\
Bled twice (\%) & $4(2)$ & $3(2)$ & $9(5)$ \\
Never bled` $(\%)$ & $4(2)$ & $8(4)$ & $1(1)$ \\
\hline Total & 186 & 192 & 188 \\
\hline
\end{tabular}

^Four of the pregnant women experienced light bleeding during follow up and three women conceived after treatment and therefore did not bleed.

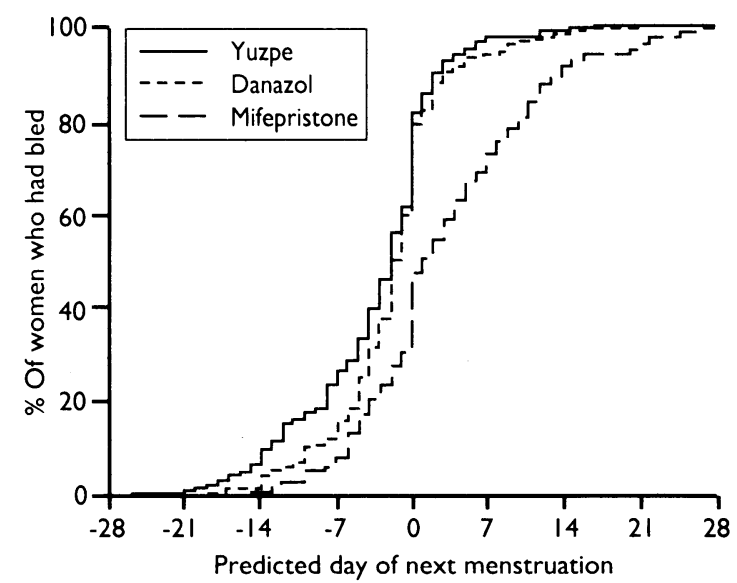

FIG 3-Cumulative graph showing percentage of women having bled relative to predicted day of next due menstruation
Yuzpe regimen induced bleeding earlier, with 71 (38\%) bleeding more than three days before the due date and only $12(6 \%)$ bleeding more than three days late. Danazol had less effect on bleeding with $57(30 \%)$ bleeding early and $17(9 \%)$ bleeding late. In the mifepristone group $36(19 \%)$ bled early and $73(39 \%)$ bled late; 49 were at least a week late, of whom 15 were over 14 days late. In the mifepristone group $61(32 \%)$ women bled more than three weeks after the unprotected intercourse compared with three $(2 \%)$ in the Yuzpe group and $11(6 \%)$ in the danazol group. Delayed bleeding seemed to cause anxiety, although this was partially allayed by measuring chorionic gonadotrophin concentration. Sixteen women had two bleeds, and it was impossible to tell clinically which one was their real period. This was seen slightly more often in the mifepristone group (nine; $5 \%$ ) than in the danazol (three; 2\%) or Yuzpe (four; 2\%) groups.

\section{Discussion}

Our results show that both the mifepristone and Yuzpe regimens are effective methods of postcoital of contraception. In the Yuzpe group the risk of pregnancy was less than half of that predicted if no treatment were given and in the mifepristone group it was nil. The upper end of the $95 \%$ confidence interval N was well below one in the mifepristone group, confirming its effect and only just above one in the Yuzpe group, suggesting it has a clinical effect.

Zuliani et al stated that danazol is a valid alternative to the Yuzpe regimen for postcoital contraception. ${ }^{12}$ They showed significant efficacy against expected $\mathbb{\Phi}$ pregnancy rates with the Yuzpe regimen and with both $800 \mathrm{mg}$ and $1200 \mathrm{mg}$ of danazol (given in three doses). We found no significant difference between the observed and predicted pregnancy rates with danazol. The standardised ratio of 0.767 was below one but the confidence interval was wide. If current pregnancy rates are assumed the number of women recruited to the danazol group would have to be more than trebled before a significant effect could be established. Any $\overrightarrow{\vec{O}}$ biological effect of danazol seemed to be so small that we did not feel morally justified to continue this arm of the study; statistical proof would have required an unacceptably high number of observed pregnancies.

The mifepristone regimen was significantly more effective than both the danazol and the Yupze regimens. Differences between the Yuzpe and danazol groups were too small to establish significance.

\section{SIDE EFFECTS AND BLEEDING PATTERNS}

The Yuzpe method frequently produced side effects, which most women would rather avoid. Both $N$ mifepristone and danazol induced minimal side $\rightarrow$ effects, which makes them more acceptable. Nevertheless, effectiveness is always the most important factor $N$ and allergy to danazol is possible.

A woman cannot be certain that she is not pregnant 0 until she has had a normal bleed. The Yuzpe method tended to induce bleeding early so that only $12(6 \%)$ women on this regimen were four or more days late and $\stackrel{\oplus}{\oplus}$ three $(2 \%)$ were over seven days late. In the mife- 0 pristone group, however, $73(39 \%)$ women bled more than three days late, of whom 49 were over seven days late.

Yuzpe et al reported that with their regimen $98 \cdot 2 \% \frac{\varrho}{0}$ of women with regular cycles bled within three weeks of treatment. ${ }^{3}$ In clinical practice this leads to a 8 warning that the next period may be early, on time, or late but if there has been no proper bleeding three흘 weeks after treatment a pregnancy test is advised. In? our study that would have led to three women in the Yuzpe group but 61 in the mifepristone group needing a test. Women requesting postcoital contraception can 
be assumed not to be planning a pregnancy. A treatment which minimised the likelihood of a delayed bleed, and therefore the requirement for a pregnancy test, would seem advantageous. The three pregnancies conceived after mifepristone treatment suggests that the next cycle and ovulation may occur without an intervening bleed. As we found no true failures of mifepristone treatment it would seem reasonable to start hormonal contraception immediately after treatment. This would give good protection against unplanned pregnancy and obviate the need for pregnancy testing unless the withdrawal bleed after the first cycle of treatment is absent.

\section{Conclusions}

Most abortions in the Western World are carried out in young women, often early on in their sexual relationships. Knowledge and availability of postcoital contraception can reduce the numbers of unplanned pregnancies and give health professionals the opportunity to encourage and supply ongoing effective contraception.

We have shown that the mifepristone and Yuzpe regimens are effective. Mifepristone has greater effectiveness and fewer side effects but leads to greater disturbance of cycle and to difficulty in predicting risk of pregnancy until the following cycle. The Yuzpe method seems to be slightly less effective and has more side effects but rarely delays the next cycle. Danazol did not seem to be effective as postcoital contraception. The risk of pregnancy for each woman can be estimated reasonably accurately by careful questioning regarding the stage of the cycle and measurement of progesterone. To determine the relative usefulness and practical effectiveness of the Yuzpe and mifepristone regimens in clinical practice we suggest a large multicentre study including all women requiring postcoital contraception, even if their level of risk is difficult to determine.

This study was funded by the special programme of research, development, and research training in human reproduction of the World Health Organisation. We thank
Brian Faragher for help with statistical analysis, Jacky Vance for persistence in achieving follow up, and Rosemary Kirkman for support and advice. 1 Haspels AA. Interception: post-coital estrogens in 3016 women. Contraception
1976;14:375-81.

2 Dixon GW, Schlesselman JJ, Ory HW, Blye RP. Ethinylestradiol and conjugated estrogens as postcoital contraceptives. FAMA 1980;244:1336-9.

3 Yuzpe AA, Smith RP, Rademaker AW. A multicentre clinical investigation emploving ethinylestradiol combined with dl-norgestrel as a postcoital contraceptive agent. Fertil Steril 1982:37.508.

4 Percival-Smith RK, Abercrombie B. Postcoital contraception with dl-norgestrel/ethinvlestradiol combination: six years' experience in a student medical clinic. Contraception 1987;36:287-93.

5 Van Santen MR, Haspels AA. A comparison of high dose estrogen versus low dose ethinylestradiol and norgestrel combination in post coital interception: a study in 493 women. Fertil Steril 1985;43:206-13.

6 Tietze C. Probability of pregnancy resulting from a single unprotected coitus Feril Steril 1960;11:485-8.

7 Barret JC, Marshall J. The risk of conception on different days of the menstrual cycle. Population Studies 1969;23:455-61.

8 Vollman RF. Assessment of the fertile and sterile phases of the menstrual cycle. International Review of Natural Family Planning 1977;1:40-7.

9 Schwartz D, Mayoux MJ, Martin-Boyce A, Czyglik F, David G. Dono insemination: conception rate according to cycle day in a series of 821 cycle with a single insemination. Fertil Steril 1979;31:226-9.

10 Department of Health. Handbook of contraceptive practice. London: $\mathrm{DoH}$ 1990

11 Rowlands S, Guillebaud J, Bounds W, Booth M. Side effects of danazol compared with an ethinylestradiol/norgestrel combination when used for postcoital contraception. Contraception 1983;27:39-49.

12 Zuliani G, Colombo UF, Molla R. Hormonal postcoital contraception with an ethinylestradiol nogestrel combination and two danazol regimes. Eur f Obstet Gynecol Reprod Biol 1990;37:253-60.

13 Van Santen MR, Haspels AA. Interception III: postcoital luteal contragestion by an antiprogestin (mifepristone, RU486) in 62 women. Contraception

14 Van Santen MR, Haspels AA. Interception IV: failure of mifepristone (RU486) as a monthly contragestive, "Lunarette." Contraception 1987:35: (RU48,

15 Lähteenmäki $\mathrm{P}$, Rapeli $\mathrm{T}$, Kääriäinen $\mathrm{M}$, Alfthan $\mathrm{H}$, Ylikorkala $\mathrm{O}$. Late postcoital treatment against pregnancy with antiprogesterone RU486. Fertil Steril 1988;50:36-8.

16 Nadler RD, Roth-Meyer C, Baulieu EE. Behavioral and endocrine consequences of long-term antiprogesterone (RU486) administration to Cynomolgus monkeys: preliminary results. In: Baulieu EE, Segal SJ, eds. The antiprogestin steroid RU486 and human fertility control. New York: Plenum Press, 1985:169-77.

17 Hermann $W^{\prime}$ L, Schindler AM, Wyss R, Bischof P. Effects of the antiprogesterone RU486 in early pregnancy and during the menstrual cycle. In: Baulieu EF Segal SJ, eds. The antipropestin steroid RU486 and human fecility control. New York: Plenum Press, 1985:199-209.

18 Fasoli M, Parazzini F, Cecchetti G, Lavecchia C. Postcoital contraception: an overview of published studies. Contraception 1989;39:459-68.

19 Gardner MJ, Altman DG. Statistics with confidence. London: British Medical Journal, 1989 .

20 Dhont $M$, Thiery $M$, Vandekerckhove D. Human chorionic gonadotrophin (HCG) assay in the diagnosis and management of early pregnancy disorders. f Obstet Gynecol 1982;2:134-9.

(Accepted 3 September 1992)
Department of Medicine 1, Southampton General Hospital, Southampton SO9 4XY

James R W Wilkinson, registrar

J Alan Roberts, senior registrar

Peter Bradding, research

fellow

Stephen T Holgate, $M R C$ professor of immunopharmacology

Peter H Howarth, senior

lecturer in medicine

Correspondence to:

Dr Wilkinson.

BMf 1992;305:931-2

\section{Paradoxical bronchoconstriction in asthmatic patients after salmeterol by metered dose inhaler}

\author{
James R W Wilkinson, J Alan Roberts, \\ Peter Bradding, Stephen T Holgate, \\ Peter H Howarth
}

Salmeterol is a long acting $\beta_{2}$ agonist used as a bronchodilator in asthma. Patients have been reported as suffering acute deteriorations in their asthma, often within minutes of exposure to salmeterol and against a background of stable asthma. ${ }^{1}$ We report six cases of acute bronchospasm induced by inhaling salmeterol by metered dose inhaler but not by dry powder inhaler (diskhaler).

\section{Patients, methods, and results}

Five female and one male asthmatic patient (aged 17-48 years, mean 28) complained of breathlessness, wheeze, or cough after inhaling salmeterol. All subjects were taking inhaled salbutamol as necessary; five were taking regular beclomethasone, and one additional prednisolone. One subject took regular salmeterol (by diskhaler), one oral salbutamol, and one oral theophylline. Forced expiratory volume in one second at rest ranged from $69 \%$ to $105 \%$ of predicted values for age, sex, and height.

All subjects attended on three occasions, when they received two puffs of salmeterol or placebo by metered dose inhaler given double blind and in random order or salmeterol $50 \mu \mathrm{g}$ by diskhaler. On two further visits four subjects received beclomethasone (Becotide) $100 \mu \mathrm{g}$ and three salbutamol (Ventolin) $200 \mu \mathrm{g}$ (given double blind in random order) (see figure). Intervals between treatments were 2-14 days. All subjects abstained from taking salmeterol for 24 hours and salbutamol for six hours before challenge. Forced expiratory volume in one second was measured before and at one, three, five, 10, 15, and 30 minutes after exposure.

Maximal percentage fall in forced expiratory volume in one second relative to baseline values was compared between treatments using Student's $t$ test for paired samples.

The figure shows the changes in forced expiratory volume in one second after the different treatments. In all subjects forced expiratory volume in one second fell substantially after inhalation of either salmeterol $(13.2 \%$ (SE $2.5 \%), p=0.005)$ or placebo $(19.0 \%$ $(3 \cdot 2 \%), \quad p=0.015)$ by metered dose inhaler. Two 